\title{
Muito além da cigarra e da formiga
}

Far beyond the ant and the grasshopper

\author{
Ana Raquel Motta* \\ Pontifícia Universidade Católica de São Paulo - São Paulo - São Paulo - Brasil
}

$\diamond$

Resumo: As práticas discursivas intersemióticas presentes nos cantos de trabalho são aqui abordadas através de triangulação teórica entre a análise enunciativa do discurso, a ergologia e a etnomusicologia. O objetivo principal é analisar o modo pelo qual muitas experiências humanas, em diversas culturas, desmentem o discurso da "Cigarra e da Formiga", que caracterizo como o discurso que vincula a música (indexando toda a arte) à ociosidade, que desvincula a música da vida cotidiana e que considera o trabalho apenas um peso, uma atividade meio, em que o prazer não se faz presente. Um vídeo sobre o trabalho em uma Casa de Farinha da Comunidade de Barreiras no município de Barrocas, no Estado da Bahia (Brasil) é descrito e analisado, possibilitando a conclusão de que, em mutirões em que se trabalha cantando, o corpo-si (cf. SCHWARTZ) integra aspectos da identidade, do cumprimento da tarefa e da memória coletiva do grupo.

Palavras-chave: Linguagem e trabalho; Ergologia; Práticas discursivas intersemióticas; Cantos de trabalho

\begin{abstract}
The intersemiotic discursive practices present in work songs are addressed here through theoretical triangulation between enunciative analysis of discourse, ergology and ethnomusicology. The main objective is to analyze how many human experiences in various cultures belie the discourse of "The Ant and the Grasshoper", that I characterize as the discourse that links music (indexing all art) to idleness, which decouples the music of everyday life. And as the other side of the coin, which considers the work just a burden, just a way to reach something, in which pleasure is not present. A video about working in a flour mill in the Barreiras Community, in the city of Barrocas in the State of Bahia (Brazil) is described and analyzed, allowing the conclusion that, in task forces where they sing while they work, the body-self (cf. SCHWARTZ) integrates aspects of identity, the fulfillment of the task and the collective memory of the group.
\end{abstract}

Keywords: Language and work; Ergology; Intersemiotic discursive practices; Work songs

\section{Linguagem, trabalho e música}

A investigação da relação entre a linguagem e o trabalho constitui uma linha de pesquisa bem estabelecida pelo menos há duas décadas na área da Linguística Aplicada no Brasil. O presente artigo se insere nesta linha de pesquisa, mas inclui um terceiro elemento, também universal e também uma prática humana, a música. Primeiramente penso que é bom explicar por que e como concebo estes três elementos como universais humanos e também por que os concebo como práticas.

Comecemos pela linguagem, e comecemos falando um pouco indistintamente de "linguagem verbal" e "língua". Todas as sociedades humanas de que se têm notícia desenvolveram e desenvolvem algum tipo de linguagem verbal, em que os signos linguísticos são organizados a partir de um arranjo de possibilidades (cf. SAUSSURE, 1916). Os linguistas podem divergir sobre o quanto podemos considerar essas possibilidades um sistema, ou sobre o quanto esse sistema é aberto ${ }^{1}$.

\footnotetext{
* Bolsista de Pós-doutorado da FAPESP e visiting Scholar in University of Texas at Austin.

1 Essa questão é bastante debatida e está presente, por exemplo, em Bakhtin/ Voloshinov (1929), quando caracterizam o "objetivismo abstrato"; também em Pêcheux (1975), quando fala sobre a "autonomia relativa da língua". Bourdieu (1982) aborda o assunto, ao conceber os sistemas linguísticos como "estruturas estruturadas e estruturantes". Dois trabalhos recentes, no Brasil, podem ser citados como atualizadores desta discussão: a primeira pergunta do livro de entrevistas Conversas com Linguistas: virtudes e controvérsias da linguística (XAVIER; CORTEZ, 2003),
} 
Também podem divergir sobre o quanto podemos encontrar características universais válidas para todas as línguas ou sobre quais são estas características ${ }^{2}$. Apesar de diferenças e ressalvas, é possível afirmar que em qualquer concepção do que sejam os seres humanos, a linguagem verbal é apresentada como uma característica central.

O mesmo se dá com o trabalho. Em todas as épocas e espaços, as mulheres e os homens trabalham, ou seja, empenham seus corpos (o que inclui suas mentes) em atividades a fim de produzir sua subsistência.

E com a música também não é diferente. Todas as sociedades desenvolvem maneiras de organizar os sons e o silêncio, os ritmos, os timbres e as melodias, seja com o uso de instrumentos, seja com o próprio corpo e voz humanos. John Blacking, em How Musical is Man?, caracteriza a música como "sons humanamente organizados" (1973, p. 10), caracterização que rapidamente se torna pouco útil na distinção entre "música" e "língua". Tal falta de especificidade pode revelar algo sobre uma possível origem comum entre a fala e o canto, conforme apontado por pesquisadores importantes como Charles Darwin (1871) ou o etnomusicólogo Bruno Nettl (1956).

Dizer que estes três elementos são universais humanos não implica, aqui, considerá-los apenas em seu aspecto bio-psicológico, o que sem dúvida deve também ser objetivo de pesquisas. Considero esses três elementos universais, mas ressalto o que eles têm de socialmente tecido, culturalmente organizado, historicamente construído.

Em outras palavras, considero a "linguagem", o "trabalho" e a "música" como práticas, tanto no sentido de que são, mais do que ideias, ações; e também porque se realizam nos grupos, o que significa que não as considerarei como produtos, e sim como processos situados em uma comunidade.

Sobre a linguagem, concebo-a como discurso, enunciados cuja aparição e sentido só podem ser entendidos sócio-historicamente (cf. SOUZA-E-SILVA; MOTTA, 2013).

A abordagem das diferentes situações de trabalho se dá a partir da ergologia, que o considera uma atividade humana, encontro de encontros, plena de debates de normas e valores e sempre a ser tecida através das renormalizações.

em que destacados linguistas brasileiros respondem "Que é língua?", apresenta uma gama de respostas que, fora algumas poucas exceções, transitam em torno da ausência ou presença de um sistema, e o grau de fixidez deste. Di Fanti e Barbisan (2012) discutem a questão do fechamento do sistema linguístico, levando em conta a publicação dos Escritos de Linguística Geral de Saussure (2002).

2 A recente polêmica levantada por Daniel Everett (2005), com base em análises da língua Pirahã, alimenta a discussão sobre os universais linguísticos propostos pela gramática gerativa.
Quanto à música, vê-la como prática implica vê-la em cultura e, mais do que isso, vê-la como cultura. Não apenas algo que se pratica dentro de tradições, valores e sistemas compartilhados, mas algo que forma e transforma esse compartilhamento. Refazendo o caminho percorrido pela etnomusicologia, o estudo da música "em contexto" passa a ser o da música "em cultura" e então, atualmente, o estudo da música "como cultura" (cf. NETTL, 2005).

Creio que o conceito de práticas discursivas intersemióticas, postulado por Dominique Maingueneau em Gênese dos Discursos (1984), ainda pode ganhar mais atenção e desdobramentos consequentes, que nos levem à radicalidade de sua proposta. Venho procurando, desde meus estudos sobre o rap brasileiro (MOTTA, 2004, 2009), contribuir para a efetivação das hipóteses 5 e 6 de Gênese dos Discursos, isto é, passar "Do discurso à prática discursiva" e considerar as "Práticas Discursivas Intersemióticas".

\section{A cigarra e a formiga}

O principal objetivo do presente artigo é analisar como muitas experiências humanas, em diversas culturas, desmentem o discurso da "Cigarra e da Formiga", que caracterizo aqui como o discurso que vincula a música (indexando toda a arte) à ociosidade, que desvincula a música da vida cotidiana. E, como outro lado da moeda, que considera o trabalho apenas um peso, uma atividade meio, em que o prazer não se faz presente.

Não discutirei as variadas formas em que esta fábula se apresenta (ver MOTTA, 2013), apenas mencionarei que está presente em muitas culturas, como as antigas (grega e romana, por exemplo) e as sociedades europeias medievais. Trata-se de uma história que permanece como cena validada (cf. MAINGUENEAU, 2006) em muitos discursos contemporâneos, conforme poderemos ver em um breve exemplo.

Em sua forma mais conhecida, a Formiga passa o verão trabalhando e acumulando provisões em sua casa, enquanto a Cigarra passa o verão cantando. Quando o inverno chega, a Formiga está aquecida e abastecida de alimento, enquanto a Cigarra passa fome e frio, sem ter onde morar nem o que comer. Sendo assim, ela recorre à Formiga, pedindo auxílio, e recebe uma lição como resposta: "Você não passou o verão cantando? Então agora dance." Em algumas versões a Cigarra morre de frio na neve, em outras apenas passa frio enquanto vê a Formiga aquecida e alimentada.

Essa fábula é retomada, por exemplo, na charge de Gerson Kauer, publicada no site "Espaço Vital Independente" - que se diz "o melhor saite jurídico da internet brasileira" -, ilustrando a coluna "Contador de Causos" de 03 de março de 2009. 


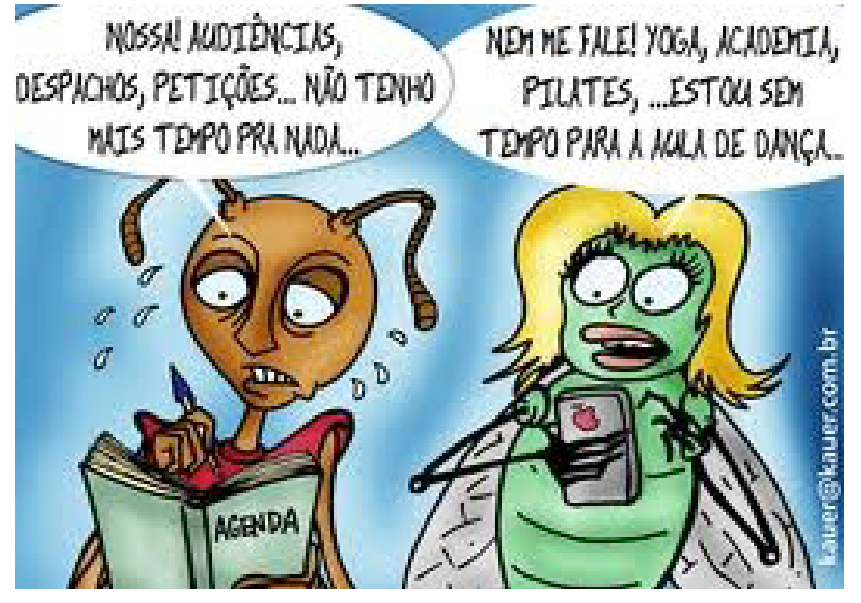

Figura 1. Charge de Gerson Kauer, publicada em <http:// www.espacovital.com.br/consulta/noticia-14086-cigarra-eformiga-uma-releitura $>$.

Há bastante para dizer sobre essa charge e o discurso de que ela participa, o que fica ainda mais interessante se lermos o texto a que ela se propõe como ilustração. Para meu presente objetivo, vou apenas levantar alguns aspectos, como o do aprofundamento, em relação à fábula original, da visão da arte como ociosidade, como banalidade, sem ligação com a vida cotidiana; e do trabalho como um peso. Há também uma questão de gênero, o homem representando o aspecto sério e relevante da vida, e a mulher, mais especificamente a mulher loira, que só pensa em banalidades e futilidades. Outra contraposição presente na charge é entre o trabalho, aqui considerado na materialidade das "audiências", "despachos" e "petições", e a busca do bem-estar físico e espiritual, materializado na "yoga", "academia", "pilates" e "aula de dança", como banalidades e futilidades de uma loira. Como último aspecto, abordarei a contraposição entre, de um lado, a seriedade da olheira, do suor e do caderno e, de outro, a futilidade da tecnologia e do consumismo, representada aqui pelo smartphone da marca Apple.

\section{A música e o triplo nascimento do trabalho}

Pensando o trabalho a partir da ergologia, vemos que uma de suas características principais são as renormalizações, que, como brilhantemente mostra Schwartz (2010), na Reflexão em torno de um exemplo de trabalho operário, estão presentes mesmo nos trabalhos que, apenas como "turistas industriais" (p.40), poderíamos considerar totalmente assujeitados e repetitivos. A ergologia nos ensina a pensar que todo o trabalho é criativo, e, a partir dela, tenho trilhado a ideia de que a arte também participa das questões cotidianas, e que podemos ver a atividade cotidiana humana como obra de arte.
Para compreender a universalidade do trabalho, ou mais precisamente da atividade de trabalho, segundo a ergologia, Schwartz (2011) localiza um triplo nascimento do trabalho: o primeiro marco, o Paleolítico, datado de aproximadamente 2.500.000 anos, caracteriza o homem genericamente como espécie, assinala o início da fabricação de objetos, das primeiras ferramentas mediando a relação dos grupos humanos com o ambiente em que vivem.

O segundo marco se localiza há aproximadamente 7.500 anos a.C., e refere-se ao nascimento de sociedades de produção, sedentarizadas, com agricultura e pecuária. Esse importante passo na história ampla da humanidade foi nomeado por Gordon Childe (1935) como "Revolução Neolítica".

O terceiro marco, que corresponde ao que hoje normalmente se considera "trabalho", abarca a prestação de serviços remunerada em uma sociedade mercantil e de direito. Podemos, grosso modo, localizar seu início na segunda metade do Século XVIII, período em que aconteceu a chamada Revolução Industrial.

Schwartz tece importantes considerações para que, a partir da ergologia, repensemos o conceito de "atividade de trabalho". Uma delas é que desde seu primeiro nascimento, a renormalização já estava presente, pois as primeiras ferramentas encontradas nos Ateliês do Paleolítico diferem entre si. A renormalização faz parte de toda atividade de trabalho realizada a partir da Revolução Neolítica e também a partir do terceiro nascimento, até em situações em que o ser humano pode parecer quase totalmente apagado, como na linha de montagem taylorista.

Meu ponto central tem sido mostrar que, junto à renormalização e, em muitas situações, propiciando-a e/ou fortalecendo-a, a música e a dança têm papel fundamental no trabalho conforme caracterizado pelos três nascimentos.

Comecemos pelo primeiro nascimento. $\mathrm{O}$ homem caçador e coletor cantava e dançava, de uma forma intimamente ligada à cultura da caça e da coleta. Ted Gioia dedica todo o primeiro capítulo de seu livro Work Songs (2006) à análise da música de trabalho em sociedades caçadoras. Com relação, especificamente, ao Paleolítico, ele discute a pesquisa de Iegor Reznikoff e Michel Dauvois (1988), que realizaram um estudo acústico nas Cavernas de Lascaux, nos Pirineus Franceses. Eles mapearam as propriedades acústicas das diferentes partes das cavernas, e chegaram à significativa conclusão de que os exatos lugares onde as pinturas estavam localizadas eram aqueles que apresentavam a maior ressonância acústica. A hipótese que defendem é a de que provavelmente os grupos humanos que fizeram essas pinturas devem ter se reunido em volta delas, para cantar, dançar, ou fazer música de outra forma. Como as pinturas se relacionam 
com a caça, a hipótese mais forte é a de que os cantos e danças também se relacionem com a caça, desenvolvendo um tipo de magia simpática e/ou pedindo permissão ao animal para caçá-lo e/ou pedindo a abundância de caça.

A música está constantemente presente (em algumas culturas podemos até dizer onipresente ${ }^{3}$ ) nas atividades de trabalho relacionadas à cultura de animais ou vegetais, com significados e funções amplos e variados. A passagem do primeiro para o segundo nascimento do trabalho é marcada por mudanças na música de trabalho. Ao mudar a relação com os animais, a humanidade desenvolveu, por exemplo, cantos específicos de guardadores de gado, como o "aboio" brasileiro e o "yodel" dos cowboys estadunidenses e dos pastores europeus. A mudança na instrumentação dos caçadores (tambores e voz cantada) para os pastores (flautas, assobios e modulações de voz) também indica a nova relação com os animais. Na relação com os vegetais, ao passar de apenas coletores para agricultores, os grupos humanos desenvolveram novas músicas de trabalho, muitas vezes - mas não só - ligadas ao ritmo constante da atividade de cultivo.

Quanto ao terceiro nascimento, a relação da música com o trabalho permanence e, assim como a própria atividade de trabalho e as renormalizações, se apresenta hoje com muitas facetas. O uso de fones de ouvido com seleção pessoal de música, cada vez mais comum em ambientes de trabalho, pode ser considerado uma renormalização. A presença de uma música nas cozinhas dos restaurantes diferente da música no ambiente das mesas é sem dúvida um espaço de controle e poder exercido pelos trabalhadores da cozinha em sua atividade de trabalho.

É importante dizer que, assim como nas línguas, no trabalho e na música reconhecer e nomear um momento histórico não significa dizer que morreram as práticas anteriores. Para o que venho desenvolvendo nesta reflexão, podemos afirmar que o mundo conhece, num mesmo tempo histórico - o atual -, práticas do primeiro, do segundo e do terceiro nascimento do trabalho.

\section{Tem uma semente de mandioca...}

Esta convivência entre tipos de trabalho que poderiam ser caracterizados como pertencentes ao segundo

\footnotetext{
3 Sobre a onipresença da música em algumas culturas humanas, podemos mencionar, por exemplo, a caracterização que Seeger (1987, p. xiv) faz do povo Suya: "A transparência sônica dessa comunidade faz de sua vila uma sala de concerto, a organização sazonal dos cantos faz de seu ano uma série de concertos (ou uma única peça musical), e os ritos de passagem fazem de sua vida um processo pontuado por transformações conquistadas durante longos períodos de cantos". ["The sonic transparency of their community makes of their village a concert hall, the seasonal organization of songs makes of their year a concert series (or a single piece of music), and the rites of passage make of their lives a process puntuaded of transformations achieved through long periods of songs.']

4 O bonito trabalho da Companhia Cabelo de Maria pode ser conhecido no site: $<$ http://www.ciacabelodemaria.com/>
}

nascimento (cultivos artesanais de animais e vegetais) e ao terceiro nascimento do trabalho (trabalho mecanizado e regulado pela sociedade civil e de direito) é bastante presente no cotidiano de muitos grupos humanos. Nouroudine (2011), por exemplo, analisa a partir da ergologia a complexidade do trabalho dos pescadores das Ilhas Comores, questionando a hegemonia do trabalho remunerado e regulado por leis como única forma de trabalho. De norte a sul do Brasil, há práticas comunitárias e modos de viver semelhantes aos descritos e analisados por Nouroudine, como é o caso das atividades de trabalho em que cantos tradicionais se fazem presentes, encontradas no conjunto de vídeos Sons e Imagens da Terra, projeto do Núcleo de Estudos Agrários e Desenvolvimento Rural (NEAD) do Ministério do Desenvolvimento Agrário do Brasil e da Bei Editora, sediada em São Paulo.

A filmagem de dezenove comunidades de diversos estados do Brasil se deu em 2004, contando com profissionais da área de jornalismo, música e fotografia. Os vídeos em estado bruto me foram cedidos para pesquisas pela pesquisadora e musicista Renata Mattar, da Companhia Cabelo de Maria ${ }^{4}$, que fez parte do grupo de pesquisa em todas as comunidades e a quem agradeço. A atividade que analisarei a partir do vídeo é parte do trabalho na Casa de Farinha da comunidade de Barreiras, no município de Barrocas no Estado da Bahia.

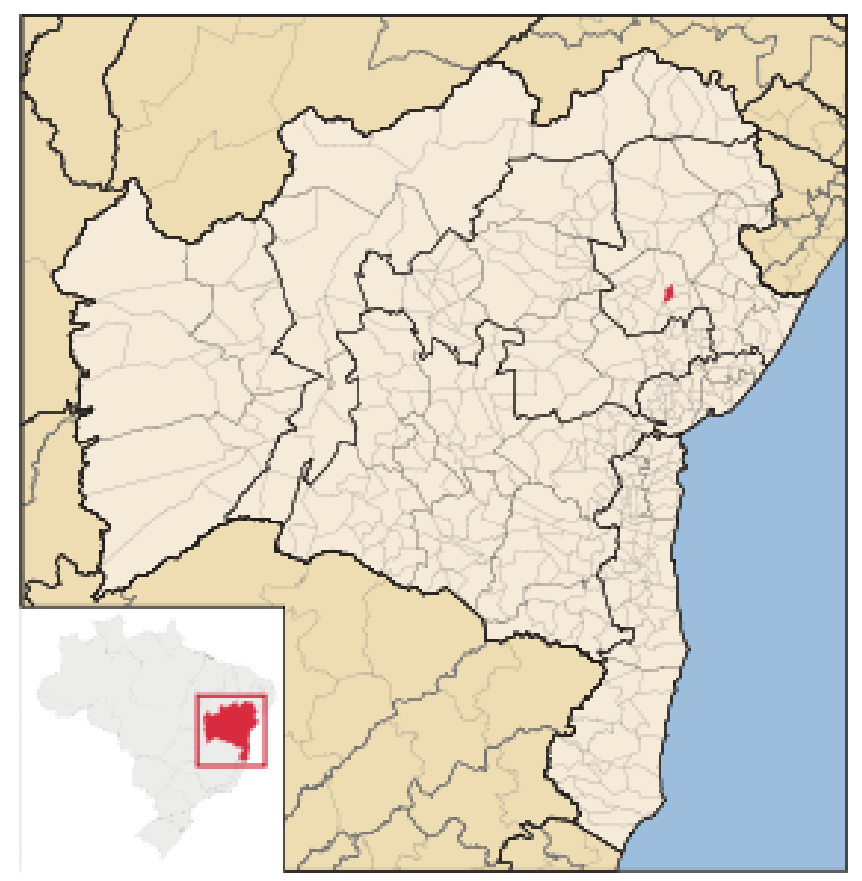

Figura 2. O ponto mais escuro no mapa maior indica a localização do município de Barrocas no Estado da Bahia, a área mais escura no mapa menor representa o Estado dentro do mapa do Brasil. Fonte: <http://pt.wikipedia.org/ wiki/Barrocas $>$. 
O plantio, a colheita e o processamento da mandioca nesta comunidade se dá de forma em parte artesanal e em parte mecanizada, e em esquema de mutirão. Após colhida, a mandioca é levada para a Casa de Farinha e descascada manualmente. Uma vez descascada, é lavada e colocada em um moedor elétrico, que a transforma numa massa, a qual é prensada até secar. Quando está seca, a mandioca ralada é peneirada manualmente e levada para o forno à lenha já aquecido, onde é mexida até atingir o ponto de torra e ser ensacada para venda. $\mathrm{O}$ grau de mecanização do processamento da mandioca pode variar de comunidade para comunidade. No caso de Barreiras, apenas a ralagem da mandioca é feita com o uso de máquina elétrica.

Analisarei apenas 1 minuto e 50 segundos de vídeo, em que é cantado um canto responsorial específico, que chamarei Semente de Mandioca. O trabalho nesta Casa de Farinha, em Barreiras, é realizado em mutirão, o que é caracterizado por um dos dois sistemas: ou a mandioca a ser ralada foi trazida por diferentes membros da comunidade e será ralada conjuntamente e depois dividida ou é a produção de um dos membros da comunidade que será processada por todos e, em um outro dia, todos auxiliarão a processar a produção de outro membro e assim por diante. Portanto, não há, nesta organização do trabalho, propriamente um patrão, no máximo um membro do grupo que é o "dono da mandioca". A relação dos membros do mutirão com o principal beneficiado no dia específico é abordada em alguns cantos de trabalho, por exemplo na Capina de Roça e na Fiação do Algodão ${ }^{5}$, mas não é o caso do canto que estou analisando aqui.

No trecho analisado, duas atividades principais estão acontecendo. Um círculo é formado por mulheres sentadas que descacam a mandioca com o uso de facas, tendo a pilha de mandiocas ao centro (Fig. 3). Três homens em pé trabalham no forno, mexendo a mandioca já ralada e seca para que torre até o ponto da farinha (Fig. 4). Portanto, na sequência da atividade em que se canta o canto Semente de Mandioca não estão incluídos nem o plantio, nem a colheita, nem a ralagem, nem a secagem, nem a peneiragem, nem o ensacamento da mandioca, e o grupo das mulheres e o dos homens trabalham em etapas diferentes e não consecutivas do processamento da mandioca na Casa de Farinha, conforme já descrevi anteriormente.

Há uma divisão do trabalho, o que inclui uma divisão dos papéis na música. Com relação às mulheres, o descasque é feito em duplas. A primeira mulher da dupla pega a mandioca e a descasca até a metade, colocando-a ao lado para que sua dupla segure a mandioca pela ponta já descascada e termine o serviço. Isso se dá para que a

\footnotetext{
5 Em Motta (2012a) analisei brevemente como a letra de um canto de trabalho, também parte deste conjunto coletado pelo NEAD, tematiza o papel da "dona da fiação", no mutirão para processamento do algodão.
}

mandioca fique mais limpa, pois apenas uma das mulheres da dupla segura a casca. No vídeo também podemos ver duas crianças (meninas) no grupo, que formam uma dupla descascando a mandioca fora do círculo, aprendendo o ofício. Quanto ao canto, a posição de primeira voz, segunda voz ou coro é revezada, de acordo com quem sabe mais cantos ou é capaz de criá-los na situação do mutirão. Desse modo, uma pessoa recém iniciada no mutirão já pode começar fazendo parte do coro, pois este evento musical participatório é feito de forma a incluir pessoas com diferentes graus de conhecimento sobre os cantos de trabalho. Turino (2008, p. 36), em suas conclusões sobre as práticas do campo musical participatório, aponta como principais características:

1. funcionam para inspirar ou apoiar participação;

2. funcionam para aumentar os laços sociais, um objetivo que frequentemente subjaz a tradições participatórias; e/ou

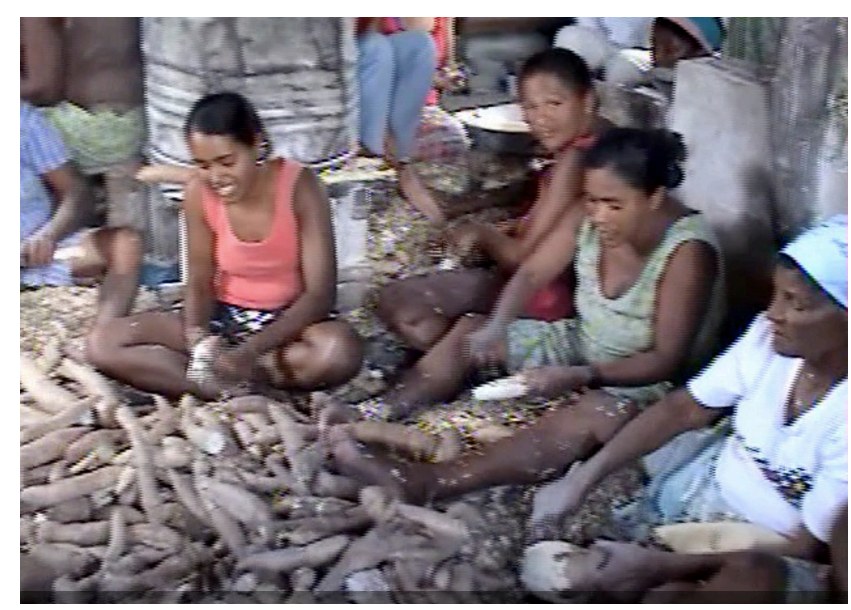

Figura 3. Mulheres trabalhando no descasque da mandioca em Barreiras, Barrocas, Bahia (Brasil), em 2004.

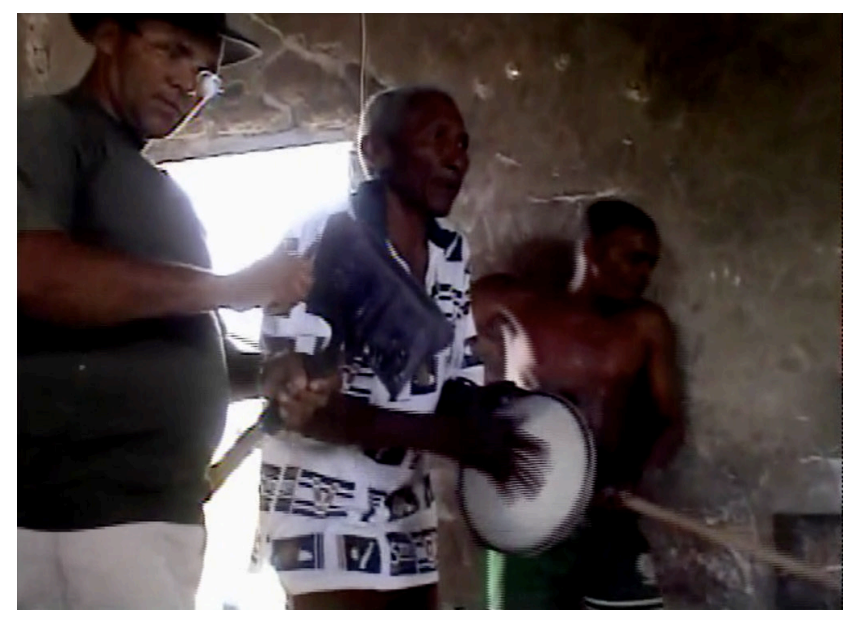

Figura 4. Homens trabalhando na torragem da mandioca em Barreiras, Barrocas, Bahia (Brasil), em 2004. 
3. dialeticamente cresceram a partir de ou foram resultado de valores e práticas participatórias. ${ }^{6}$

O trabalho dos homens também inclui participação no coro, nos instrumentos musicais e na lida com o forno. Um dos instrumentos é feito com a faca raspando em uma enxada; como é comum em muitas práticas musicais pelo mundo, o instrumento de trabalho pode ser usado como um instrumento musical. O outro instrumento é um pandeiro, nesse caso, industrializado.

Tanto homens quanto mulheres podem, em momentos do mutirão, ficar apenas cantando e marcando o ritmo com palmas ou tocando os instrumentos. Podemos ver aí uma sabedoria na lida com o corpo, intercalando as atividades e evitando muitas horas seguidas de movimento repetitivo, que sabemos ser a maior causa de adoecimento físico no trabalho para muitas ocupações.

A música se dá em ritmo binário, e pode ser caracterizada como um baião (Fig. 5). O canto é responsorial, com uma voz principal e um coro. O ritmo da música não tem relação direta com o ritmo do descasque da mandioca, influenciando apenas de uma maneira mais ampla no andamento da atividade. Já o ritmo da mexida da mandioca no forno é mais diretamente relacionado ao ritmo da música.

\section{Semente de Mandioca}
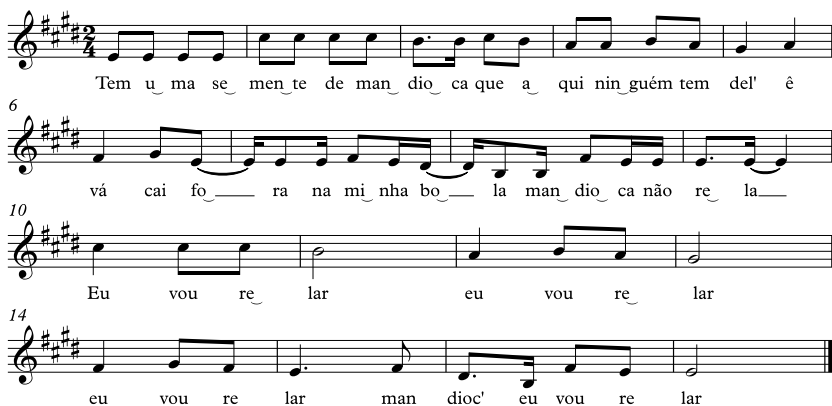

Figura 5. Transcrição da primeira voz e coro do canto de trabalho Semente de Mandioca, em Barreiras, Barrocas, Bahia (Brasil), em 2004.

$\mathrm{Na}$ letra do canto, a primeira voz, no caso feminina, fala de "uma semente de mandioca que aqui ninguém tem dela", e continua na distinção "ê, vá, cai fora, na minha bola mandioca não rela" "eu vou relar, eu vou relar, eu vou relar mandioca, eu vou relar". Esta letra faz parte do aprendizado sobre a própria atividade, pois tematiza a importância da boa escolha da semente de mandioca (também chamada de "maniva") para plantio e do isolamento necessário a cada espécie de mandioca, pois não se pode misturar dois tipos de mandioca numa mesma produção de farinha, nem em uma mesma área de plantio: as diferentes espécies devem ser isoladas.
A voz principal tematiza o momento da relagem (ou ralagem, na forma mais urbana da palavra) da mandioca e descreve o processo manual da "bola de relar", que é movida por uma engrenagem manual. Assim, os "os fios de uma memória patrimonial, inscrita em nossos corpos vivos e operantes" (SCHWARTZ, 2011, p.21) a respeito de uma prática que esta comunidade não realiza mais - a ralagem manual da mandioca - reaparece nesses corpos que cantam, enquanto trabalham em outras etapas manuais do processamento da mandioca. Portanto, a única etapa do processo que, nesta comunidade, não é mais realizada artesanalmente é especificamente a que é rememorada neste canto. Práticas iniciadas pela humanidade com o segundo e o terceiro nascimento do trabalho convivem e se tensionam nesta comunidade, através do canto de trabalho que ecoa uma atividade pré-automatização que foi substituída pela mecanização.

O coro responde que vai relar mandioca, o que produz uma redundância muito comum na música participatória e em outros tipos de arte: o poeta que escreve que está escrevendo um poema, o rapper que canta que é um bom rapper, e assim por diante. Mais que uma "meta-ação", neste caso tematizar o próprio trabalho é importante para o aprendizado da lida com a mandioca, ao mesmo tempo que, como vimos, para a manutenção da memória de uma etapa artesanal que esta comunidade não pratica mais.

\section{Corpo-si: a cigarra e a formiga}

O conceito de "'corpo-si', alguma coisa que atravessa tanto o intelectual, o cultural, quanto o fisiológico, o muscular, o sistema nervoso" (SCHWARTZ, 2010, p.44), proposto pela ergologia para compreender quem é o sujeito da atividade, auxilia a analisar o evento que acontece nesta Casa de Farinha. Vemos unidos e integrados diferentes aspectos de corpos-si que tomam a decisão sobre a boa mandioca, corpos-si que mantêm viva a memória sobre a ralagem manual, corpos-si que descascam e torram a mandioca e corpos-si que cantam e tocam ${ }^{8}$.

\footnotetext{
6 “(1) functioned to inspire or support participation; (2) functioned to enhance social bonding, a goal that often underlies participatory traditions; and/or (3) dialectically grew out of or were the result of participatory values and practices" (TURINO, 2008, p. 36).

7 Agradeço a Sírio Possenti a sugestão de que "ê, vá, cai fora" possa remeter a uma "fórmula de escolha", presente em muitas parlendas e jogos com palavras por todo o mundo. Ainda não encontrei a relação entre o canto Semente de Mandioca e este tipo de jogo, ao menos em sua presença na atividade de trabalho que está sendo analisada aqui. Obviamente isso não exclui que em algum momento de sua existência este canto tenha sido uma "fórmula de escolha", hipótese que continuarei investigando.

8 Em Motta (2012b) escrevi especificamente sobre a centralidade da noção de corpo-si para compreensão do sujeito das práticas discursivas intersemióticas.
} 
Desse modo, incluir a música na relação entre a linguagem e o trabalho pode conduzir a uma maior compreensão dessa relação, posto que em muitas culturas e mais frequentemente do que tem sido objeto de atenção nos estudos discursivos e ergológicos, a linguagem do/no trabalho é também musical. Além de estar considerando realmente as práticas discursivas como intersemióticas, ao analisar os cantos de trabalho, aspectos importantes e um tanto fugidios do corpo-si, esta "entidade um pouco enigmática" (SCHWARTZ, 2010, p. 44), podem ser acessados.

Trilhar este caminho abre clareiras para melhor compreender o trabalho e poder transformá-lo, contribuindo para que as atividades de trabalho possam ir muito além da empobrecedora divisão entre a Cigarra e a Formiga.

\section{Referências}

BAKHTIN, Mikhail; VOLOSHINOV, Valentin [1929]. Marxismo e Filosofia da Linguagem: problemas fundamentais do método sociológico na ciência da linguagem. Tradução Michel Lahud e Yara Frateschi Vieira. São Paulo: Hucitec, 1979.

BLACKING, John. How musical is man? Seattle: University of Washington Press, 1973.

BOURDIEU, Pierre [1982]. Economia das trocas linguísticas: o que falar quer dizer. Tradução Sérgio Micceli et al. São Paulo: Edusp, 1998.

CHILDE, Gordon. New Light on the Most Ancient East: The Oriental Prelude to European Prehistory. London: Kegan Paul, 1935.

DARWIN, Charles. The descent of man and selection in relation to sex. New York: D. Appleton and Company,1871.

DI FANTI, Glória; BARBISAN, Leci Borges. Apresentação. In: DI FANTI, Glória; BARBISAN, Leci Borges (Org.). Enunciação e discurso: tramas de sentidos. São Paulo: Contexto, 2012. p. 7-10.

EVERETT, Daniel. Cultural Constraints on Grammar and Cognition in Pirahã. Current Anthropology, v. 46, n. 4, p.621646, Aug.-Oct. 2005.

GIOIA, Ted. Work Songs. Duham, NC: Duke University Press, 2006.

MAINGUENEAU, Dominique [1984]. Gênese dos Discursos. Tradução Sírio Possenti. Curitiba, PR: Criar, 2005.

MAINGUENEAU, Dominique. Cenas da Enunciação. Organização de Sírio Possenti e Maria Cecília Perez de Souzae-Silva. Curitiba: Criar, 2006.

MOTTA, Ana Raquel. Trabalho e arte em um curta de Walt Disney. In: ABRIATA, V. L. R.; CÂMARA, N. S.; RODRIGUES, M. G.; SCHWARTZMANN, M.N. (Org.). Coleção Mestrado em Linguística. 1. ed. Franca: Universidade de Franca, 2013. v. 8 , p. $125-142$.

MOTTA, Ana Raquel. Chants de Travail. Actes du Premier Congres de la Société Internationale d'Ergologie. Strasbourg: Université de Strasbourg, 2012a. p. 203-208.
MOTTA, Ana Raquel. Análise do Discurso e Ergologia: o sujeito na atividade de trabalho. Moara, n. 38, p. 70-80, jul.dez. 2012 b.

MOTTA, Ana Raquel. Heterogeneidade e aforização. Uma análise do discurso dos Racionais MCs. 323 fls. Tese (Doutorado em Linguística) - Universidade Estadual de Campinas, Campinas, 2009.

MOTTA, Ana Raquel. "A favela de influência". Uma análise das práticas discursivas dos Racionais MCs. 306 fls. Dissertação (Mestrado em Linguística) - Universidade Estadual de Campinas, Campinas, 2004.

NETTL, Bruno. Music in Primitive Culture. Cambridge, MA: Harvard University Press, 1956.

NETTL, Bruno. Music and that complex whole: music in culture. In: NETTL, Bruno. The study of Etnomusicology: tirdyone studies and concepts. Urbana, IL: University of Illinois Press, 2007.

NOUROUDINE, Abdallah. Como conhecer o trabalho quando o trabalho não é mais o trabalho? Trabalho, Educação e Saúde, v. 9, supl. 1, p. 69-83, 2011.

PÊCHEUX, Michael. [1975]. Semântica e discurso - uma crítica à afirmação do óbvio. Tradução Eni Orlandi. Campinas, SP: Editora da Unicamp, 1988.

REZNIKOFF, Iegor; DAUVOIS, Michel. La dimension sonore des grottes ornées. Bulletin de Ia Société Prehistorique Française, n. 85, p. 238-46, 1988.

SAUSSURE, Ferdinand. [1916]. Curso de Linguística Geral. Tradução de Antônio Chelini, José Paulo Paes e Izidoro Blikistein. São Paulo: Cultrix, 1970.

SAUSSURE, Ferdinand. Escritos de Linguística Geral. Organizados e editados por Simon Bouquet e Rudolf Engler. Tradução Carlos Augusto Leuba Salum e Ana Lúcia Franco. São Paulo: Cultrix, 2002.

SCHWARTZ, Yves. Reflexão em torno de um exemplo de trabalho operário. Tradução Jussara Brito. In: SCHWARTZ, Yves; DURRIVE, Louis (Org.). Trabalho e ergologia: conversas sobre a atividade humana. 2. ed. revista e ampliada. Niterói, RJ: Editora da Universidade Federal Fluminense, 2010.

SCHWARTZ, Yves. Conceituando o trabalho: o visível e o invisível. Trabalho, Educação e Saúde, v. 9, supl. 1, p. 19-45, 2011.

SEEGER, Anthony. Why Suya Sing: a musical anthropology of an amazonian people. Cambridge: Cambridge University Press, 1987.

SOUZA-E-SILVA, Cecília; MOTTA, Ana Raquel. Le langage et le travail Rapprochements entre 1 approche ergologique et les études du langage. Ergologia, v. 9, p. 90-112, 2013.

XAVIER, Antonio Carlos; CORTEZ, Suzana (Org.). Conversas com linguistas: virtudes e controvérsias da Linguística. São Paulo: Parábola Editorial, 2003.

Recebido: 14 de novembro de 2013 Aprovado: 04 de janeiro de 2014

Contato: anaraquelms@gmail.com 